\title{
Epidermoid cyst: A single-center review of 432 cases
}

\author{
Choon Soo Kim ${ }^{1}$, \\ Young Cheon $\mathrm{Na}^{1}$, \\ Chi Sun Yun ${ }^{1}$, \\ Woo Hoe Huh ${ }^{1}$, \\ Bo Ra Lim² \\ Departments of ${ }^{1}$ Plastic and \\ Reconstructive Surgery and \\ ${ }^{2}$ Dermatology, Wonkwang University \\ Hospital, Iksan, Korea
}

\begin{abstract}
Background: Epidermoid cysts are benign tumors derived from the infundibular portion of hair follicles and thus have a flattened surface epithelium and keratohyaline granules. They can occur at any age but are most frequently reported in adults, and more often occur in men than women. Most epidermoid cyst operations are performed for cosmetic purposes, or to relieve inflammation. The definitive treatment is complete excision or destruction of the cyst. The aim of this study was to improve understanding of epidermoid cysts.

Methods: We analyzed 432 cases of epidermoid cyst in 398 patients that underwent complete excision and biopsy between April 2001 and March 2020, according to patient age, patient gender, and lesion location.

Results: From all epidermoid cyst excisions performed, 17.6\% were for patients in their 40 s and 50 s, $16.8 \%$ for those in their 20s, $16.1 \%$ for those in their 30 s, $14.6 \%$ for those aged 60 or older, $5.0 \%$ for teenagers, and $0.5 \%$ for those under 10 years. Cases of epidermoid cysts occurred at a men-to-women ratio of about 3:2, with 59.5\% of cases in men and $40.5 \%$ in women. By lesion location, $65.0 \%$ of cases were on the face, $10.9 \%$ on the trunk, $7.9 \%$ on the scalp, $7.9 \%$ on the neck, $4.3 \%$ on lower extremities, $3.9 \%$ on upper extremities, and $0.2 \%$ on genitalia. On the face, $20.8 \%$ of cases were on the cheek, $12.7 \%$ on the periauricular area, $10.9 \%$ on the periorbital area, $6.0 \%$ on the frontal area, $5.6 \%$ on the mental area, $3.7 \%$ on the perioral area, $2.8 \%$ on the nasal area, and $2.5 \%$ on the temporal area.

Conclusion: The proportion of women with epidermoid cysts was higher in our study than in previous studies. Moreover, the results showed that surgery has been on the rise in recent years, with facial surgery being the most common.
\end{abstract}

Keywords: Biopsy / Epidermoid cyst / Face

\section{INTRODUCTION}

Epidermoid cysts are benign tumors also known as follicular cysts-infundibular type, keratin cysts, epidermal cysts, epidermal inclusion cysts, or epithelial cysts [1]. They can be congenital or acquired $[1,2]$ and are derived from the infundibular portion of hair follicles. As such, the surface epithelium is flattened

Correspondence: Young Cheon Na

Department of Plastic and Reconstructive Surgery, Wonkwang University Hospital, 895 Muwang-ro, Iksan 54538, Korea

E-mail: ycnadr@hanmail.net

This work was supported by Wonkwang University Hospital in 2020.

Received June 5, 2020 / Revised June 16, 2020 / Accepted June 19, 2020 and contains keratohyaline granules $[1,3]$. They occur at any age but are more common among adults, and among men [1,4]. The aim of this study was to improve understanding of epidermoid cysts by comparing and analyzing epidermoid cyst cases in which total excision and biopsy had been performed over a 20-year period.

\section{METHODS}

This retrospective study was conducted via chart review of the gender, age, lesion location, operation year, underlying disease, and complications of 432 cases of epidermoid cyst in 398 pa- 
tients who underwent total excision and biopsy between April 2001 and March 2020. In cases with infection, surgery was performed once infection subsided following the administration of antibiotics and anti-inflammatory drugs for at least 1 to 2 weeks. The operation consisted of the removal of the entire cyst and primary closure of the operation site. The cyst that was removed en bloc by the elliptical removal of part of the skin including the punctum was sent for permanent section biopsy.

\section{RESULT}

\section{Distribution by gender and age}

The age range of patients was 6-96 years, with patients in their $40 \mathrm{~s}$ and 50s accounting for the largest proportion of patients (each with 70 cases, representing $17.6 \%$ each), followed by patients in their 20s (67 cases; 16.8\%), patients in their 30s (64 cases; $16.1 \%$ ), and patients in their 60 s (58 cases; $14.6 \%$ ). There were a total of 261 lesions in 237 men and 171 lesions in 161 women (men vs. women: $59.5 \%$ vs $40.5 \%$ of patients, $60.4 \%$ vs. $39.6 \%$ of lesions) (Tables 1, 2).

\section{Distribution by location of lesions}

The distribution of lesions on the body was as follows: face 281 cases (65.0\%); trunk 47 cases (10.9\%); scalp 34 cases (7.9\%); neck 34 cases (7.9\%); lower extremities 18 cases (4.3\%); upper

Table 1. Distribution by sex and age

\begin{tabular}{cccc}
\hline \multirow{2}{*}{ Variable } & \multicolumn{2}{c}{ Sex } & \multirow{2}{*}{ Total (\%) } \\
\cline { 2 - 3 } & Male & Female & \\
\hline Age (yr) & & & \\
$<10$ & 0 & 2 & $2(0.5)$ \\
$10-19$ & 9 & 11 & $20(5.0)$ \\
$20-29$ & 48 & 19 & $67(16.8)$ \\
$30-39$ & 40 & 24 & $64(16.1)$ \\
$40-49$ & 42 & 28 & $70(17.6)$ \\
$50-59$ & 44 & 26 & $70(17.6)$ \\
$60-69$ & 34 & 24 & $58(14.6)$ \\
$70-79$ & 10 & 16 & $26(6.5)$ \\
$>79$ & 10 & 11 & $21(5.3)$ \\
Total (\%) & $237(59.5)$ & $161(40.5)$ & $398(100)$ \\
\hline
\end{tabular}

Table 2. Distribution by the number of lesions

\begin{tabular}{lcccc}
\hline Sex & \multicolumn{3}{c}{ No. of lesions } & $\begin{array}{c}\text { Total } \\
\text { (patients/lesions) }\end{array}$ \\
\cline { 2 - 4 } Male & 1 & 2 & 3 & $237 / 261$ \\
Female & 215 & 20 & 2 & $161 / 171$ \\
Total & 151 & 10 & 0 & $398 / 432$ \\
\hline
\end{tabular}

extremities 17 cases (3.8\%); genitalia one case (0.2\%) (Table 3). On the face, $20.8 \%$ of lesions were on the cheek, $12.7 \%$ were in the periauricular area, $10.9 \%$ were in the periorbital area, $6.0 \%$ were in the frontal area, 5.6\% were in the mental area, 3.7\% were in the perioral area, $2.8 \%$ were in the nasal area, and $2.5 \%$ were in the temporal area (Table 3 ).

\section{Distribution by year}

A total of 432 cases diagnosed between April 2001 and March 2020 were investigated on an annual basis (Fig. 1).

\section{Underlying diseases}

There were 98 patients with underlying diseases (Tables 4, 5).

Table 3. Distribution by location of lesions

\begin{tabular}{lc}
\hline Location & No. of cases (\%) \\
\hline Face & $281(65.0)$ \\
Frontal & $26(6.0)$ \\
Orbital & $47(10.9)$ \\
Auricular & $55(12.7)$ \\
Nose & $12(2.8)$ \\
Cheek & $90(20.8)$ \\
Temporal & $11(2.5)$ \\
Labial & $16(3.7)$ \\
Mental & $24(5.6)$ \\
Scalp & $34(7.9)$ \\
Neck & $34(7.9)$ \\
Trunk & $47(10.9)$ \\
Back & $34(7.9)$ \\
Chest & $9(2.1)$ \\
Abdomen & $1(0.2)$ \\
Axilla & $3(0.7)$ \\
Upper extremities & $17(3.8)$ \\
Shoulder & $532(100)$ \\
Upper arm & $1(1.1)$ \\
Forearm & $1(0.2)$ \\
Wrist & $1(0.2)$ \\
Hand & $1(0.2)$ \\
Lower extremities & $9(2.1)$ \\
Buttock & $1(4.3)$ \\
Kootigh & $7(1.7)$ \\
\hline & $6(1.4)$ \\
Knee & $2(0.5)$ \\
\hline Lotalia & \\
\hline
\end{tabular}




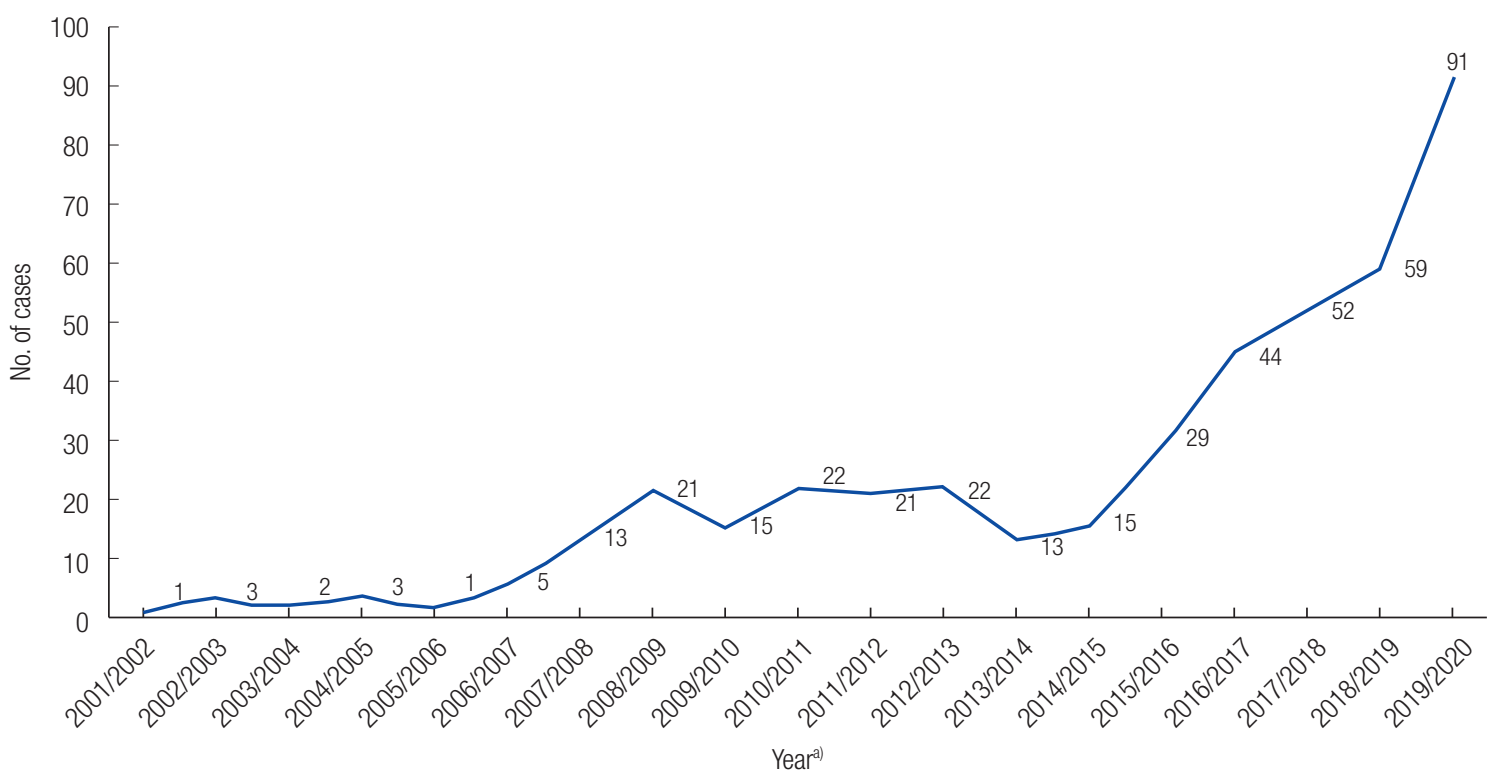

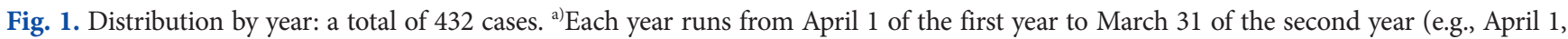
2001, to March 31, 2002).

Table 4. Distribution according to the presence and number of underlying diseases

\begin{tabular}{lc}
\hline Underlying disease & No. of patients (\%) \\
\hline Present & $98(24.6)$ \\
1 Disease & $55(13.8)$ \\
2 Diseases & $31(7.8)$ \\
3 Diseases & $11(2.8)$ \\
4 Diseases & $1(0.2)$ \\
Absent & $300(75.4)$ \\
Total & $398(100)$ \\
\hline
\end{tabular}

\section{Complications}

There were no cases with complications, such as recurrence or infection.

\section{DISCUSSION}

Cutaneous cysts can be divided into three types according to their morphology and specific pattern of differentiation: (1) stratified squamous epithelium; (2) non-stratified squamous epithelium; and (3) absence of epithelium [5]. Epidermoid cysts belong to the first category and are known to account for $79 \%$ of all cutaneous cysts [3].

Epidermoid cysts are relatively rare, slow-growing benign cysts [6]. They can be congenital or the result of skin damage. They are lined by an epithelium that resembles the infundibulum of the hair follicle and expresses the same cytokeratin profile [1]. They appear to be caused by epithelial invagination into the tissue; alternatively, the eccrine duct can form a cyst on an
Table 5. Number of patients according to the underlying disease

\begin{tabular}{lc}
\hline Underlying disease & No. of patients \\
\hline Hypertension & 71 \\
Diabetes mellitus & 45 \\
Hyperlipidemia & 11 \\
\hline Angina & 8 \\
\hline Cerebral infarction & 3 \\
\hline Breast cancer & 3 \\
Gastric cancer & 3 \\
Hyperthyroidism & 2 \\
\hline Colon cancer & 2 \\
End-stage renal disease & 2 \\
Prostate cancer & 1 \\
Thyroid cancer & 1 \\
Bladder cancer & 1 \\
Hypothyroidism & 1 \\
\hline
\end{tabular}

area that lacks hair follicles [1]. In addition, they can occur in genetic disorders such as Gorlin syndrome (also known as nevoid basal cell carcinoma syndrome) or Garber syndrome $[1,3]$. When epidermoid cysts occur, the diseases to be differentially diagnosed include steatocystomas, pilar cysts, lipomas, dermoid cysts, furuncles, branchial cleft cysts, milia, calcinosis cutis, pachyonychia congenita, and melanomas, amongst others $[1,5]$.

Cutaneous cysts reportedly occur more frequently in men than women; the rate has been variously reported. For example, Dutta et al. [4] reported a male-to-female ratio of 4.6:1 and Jham et al. [7] reported a ratio of 3:1. In Korea, Han and Kim 
[8] reported a ratio of 1.8:1 and Heo and $\mathrm{Oh}$ [9] reported a ratio of 2.8:1. In this study, we found that the rate of occurrence in women was higher than in these previous reports, at a male-tofemale ratio of 1.5:1. Given that epidermoid cyst removal is usually performed for cosmetic reasons, the increase in social activities of women between the time periods captured by previous studies and those captured by our study, may have driven the increased occurrence in women.

In this study the number of surgeries per year did not differ greatly between 2001 and 2015, but has risen sharply since 2015. The increase in surgery may be due to several factors. First, most recent patients have been issued medical certificates for insurance company claims which may reflect the increasing number of subscribers of loss insurance that can guarantee a reimbursement for the amount incurred for medical expenses. Second, there has been an increased interest in beauty.

Cutaneous cysts usually occur after puberty, and Han and Kim [8] reported most cases among patients in their 20s, while Heo and Oh [9] reported the most cases among patients in their 30s and 40s. In this study, epidermoid cysts were most

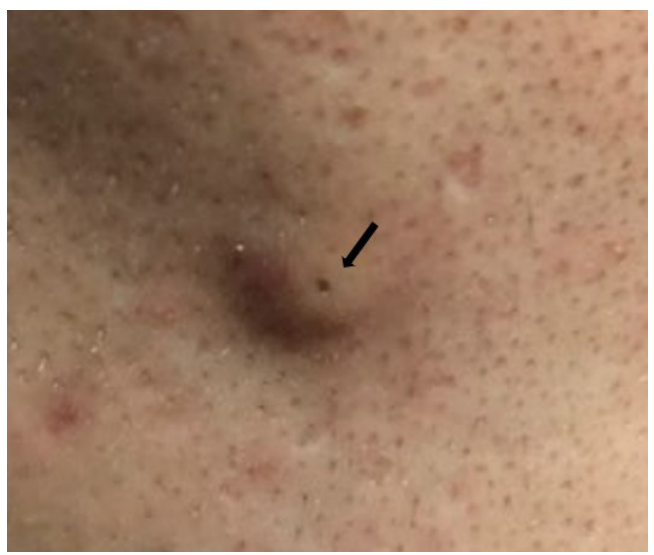

Fig. 2. A photograph of an epidermoid cyst, showing a round, movable mass and its punctum (arrow).

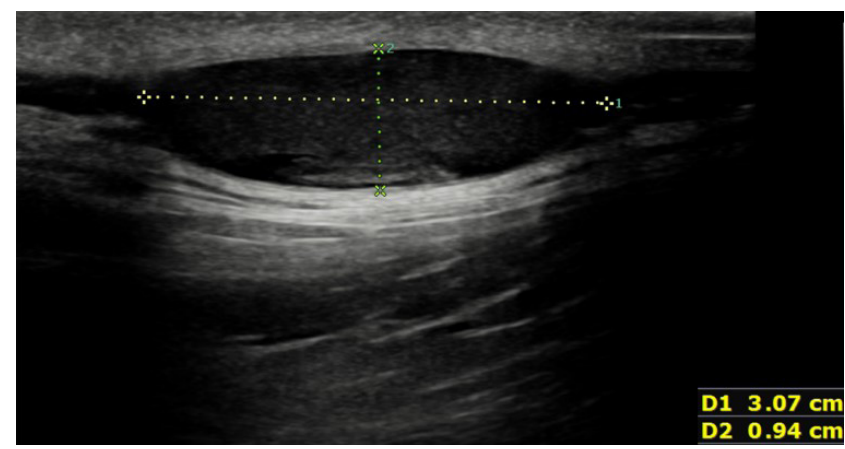

Fig. 3. A sonography image revealing an epidermoid cyst as a 3.07 $\times 0.94 \mathrm{~cm}$ well-defined, oval-shaped, hypoechoic structure located in the subcutaneous tissue. common among patients in their 40s and 50s, followed consecutively by those in their 20s, 30s, and 60s. This result is understandable, since those in their 40s and 50s are the most active generation in terms of social activities. It is, however, unusual that the surgery was performed at a relatively high rate among patients in their 60s and older, suggesting that the extent of care regarding appearance in life after retirement is gradually increasing, and that it is financially supported to the extent that surgery can be performed.

Epidermoid cysts are slow-growing, and are usually only found after reaching a certain size $[6,10]$. During physical examination, epidermoid cysts present as a painless, movable mass on the dermis or subcutaneous layer, with a keratin-filled orifice-the punctum-on the surface (Fig. 2). A noticeable characteristic is that the cyst can communicate with the skin surface through the punctum [5], and the punctum is useful for differential diagnosis from similar cysts such as dermoid cysts.

Diagnosis is performed via a number of techniques including physical examination, radiological examination, and biopsy. Radiological studies include sonography, computed tomography, and magnetic resonance imaging, and in this study we used sonography if necessary. In a sonography image, the epidermoid cyst appears as a heterogenous low echogenicity area with a slight increase in sound transmission (Fig. 3) [11]. Histologically, epidermoid cysts are lined by a stratified squamous epithelium resembling the epidermis and include a granular layer and keratin lamellae in the lumen (Fig. 4).

When considering incidence according to lesion location, Choi et al. [12] reported 23 cases on the trunk (34.3\%), nine cases on the face (12.6\%), eight cases on the neck (12.0\%), six cases on the buttocks (9.0\%), five cases on the leg $(7.5 \%)$, four cases on the scalp (6.0\%), and three cases on the foot (4.5\%).

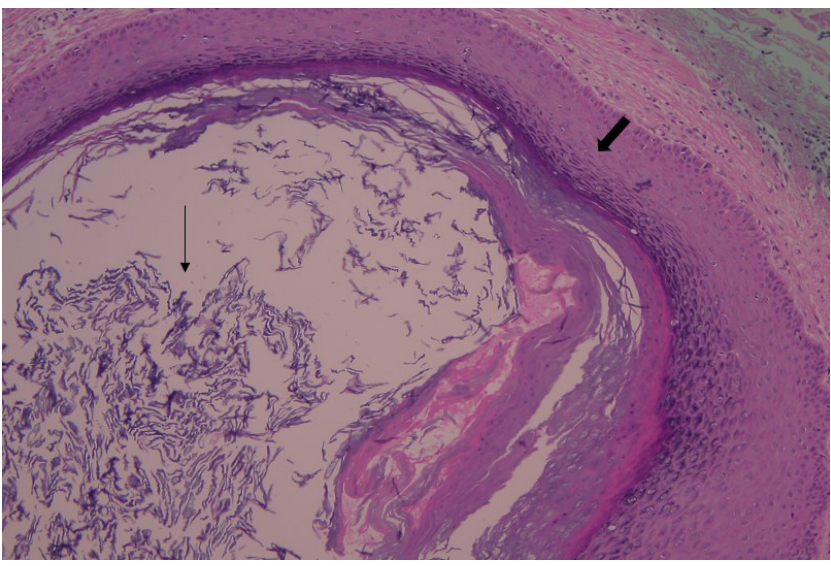

Fig. 4. Histopathologic examination. An epidermoid cyst is lined by a squamous epithelium including granular cell layers (thick arrow), and contains laminated keratin (thin arrow) $(\mathrm{H} \& \mathrm{E}, \times 100)$. 
Han and Kim [8] reported 66 cases on the trunk (21.9\%), 63 cases on the face (20.9\%), 42 cases on the neck (13.9\%), and 20 cases on the scalp (6.6\%). Sung et al. [13] reported 35 cases on the trunk, 23 cases on the face, 20 cases on lower extremities, nine cases on upper extremities, five cases on the scalp, and one case on the whole body. The figures we report in this study demonstrate an overwhelming majority of cases on the face, in contrast to previous studies that generally report the most frequent occurrence to be on the trunk. This is also thought to be driven by the growing interest in beauty and the flourishing economy in South Korea and will require continuous follow-up observation.

Underlying diseases were, in descending order of frequency, hypertension, diabetes mellitus, and hyperlipidemia. Although these did not appear to be related to the occurrence of epidermoid cysts, the relationship needs further investigation through long-term and large-scale research. Squamous cell carcinoma and basal cell carcinoma have previously been reported in rare cases of malignancy [5] but carcinoma was not detected in this study [5].

Treatment may be total excision; in some cases, the minimal excision technique presented by Zuber was used [14]. Complications such as inflammation and wound dehiscence have also been reported previously [1] but they did not occur in this study.

In this 20-year retrospective study, we report that the incidence of epidermoid cysts among women, as measured by the number of surgeries at our hospital, has increased compared to previous reports. We also report that the incidence of epidermoid cysts on the face has increased compared to previous reports.

\section{NOTES}

\section{Conflict of interest}

No potential conflict of interest relevant to this article was reported.

\section{Ethical approval}

The study was approved by the Institutional Review Board of Wonkwang University Hospital (IRB No. WKIRB-202006SB-024) and performed in accordance with the principles of the Declaration of Helsinki. Written informed consents were obtained.

\section{Patient consent}

The patients provided written informed consent for the publication and the use of their images.

\section{ORCID}

Choon Soo Kim https://orcid.org/0000-0003-2217-3175

Young Cheon Na https://orcid.org/0000-0003-3136-0351

Chi Sun Yun https://orcid.org/0000-0002-9204-9121

Woo Hoe Huh https://orcid.org/0000-0002-1379-7122

Bo Ra Lim https://orcid.org/0000-0003-1717-857X

\section{REFERENCES}

1. Kang S, Amagai M, Bruckner AL, Enk AH, Margolis DJ, McMichael AJ, et al. Fitzpatrick's dermatology. New York: McGraw-Hill Education, 2019.

2. Acarturk TO, Stofman GM. Posttraumatic epidermal inclusion cyst of the deep infratemporal fossa. Ann Plast Surg 2001;46:6871.

3. Epstein WL, Kligman AM. Epithelial cysts in buried human skin. AMA Arch Derm 1957;76:437-45.

4. Dutta M, Saha J, Biswas G, Chattopadhyay S, Sen I, Sinha R. Epidermoid cysts in head and neck: our experiences, with review of literature. Indian J Otolaryngol Head Neck Surg 2013; 65(Suppl 1):14-21.

5. Hoang VT, Trinh CT, Nguyen CH, Chansomphou V, Chansomphou V, Tran TTT. Overview of epidermoid cyst. Eur J Radiol Open 2019;6:291-301.

6. Boffano P, Roccia F, Campisi P, Zavattero E, Gallesio C, Bosco GF. Epidermoid cyst of the temporal region. Oral Surg Oral Med Oral Pathol Oral Radiol Endod 2011;112:e113-6.

7. Jham BC, Duraes GV, Jham AC, Santos CR. Epidermoid cyst of the floor of the mouth: a case report. J Can Dent Assoc 2007; 73:525-8.

8. Han YS, Kim SN. A study on 1,302 cases of skin tumor. Korean J Dermatol 1988;26:189-99.

9. Heo CY, Oh GS. A 10 year period (1989-1998) of clinical observation of facial skin tumors. Inje Med J 1999;20:361-68.

10. Ravindranath AP, Ramalingam K, Natesan A, Ramani P, Premkumar P, Thiruvengadam C. Epidermoid cysts: an exclusive palatal presentation and a case series. Int J Dermatol 2009; 48:412-5.

11. Yang DM, Yoon MH, Kim HS, Oh YH, Ha SY, Oh JH, et al. Presacral epidermoid cyst: imaging findings with histopathologic correlation. Abdom Imaging 2001;26:79-82.

12. Choi JS, Shin S, Kim MS, Park MH, Park HS. A statistical survey of skin tumors. Korean J Dermatol 1978;16:9-18.

13. Sung KY, Kim YD, Kim DW, Chung SL. A statistical review of benign tumors of the skin for the past 10 years. Korean J Dermatol 1988;26:879-89.

14. Zuber TJ. Minimal excision technique for epidermoid (sebaceous) cysts. Am Fam Physician 2002;65:1409-20. 